\title{
Lymphatic metastasis of breast cancer cells is associated with differential gene expression profiles that predict cancer stem cell-like properties and the ability to survive, establish and grow in a foreign environment
}

\author{
TERLIKA S. PANDIT ${ }^{1}$, WENDY KENNETTE ${ }^{1}$, LISA MacKENZIE ${ }^{1}$, GUIHUA ZHANG ${ }^{1}$, WALEED AL-KATIB ${ }^{1}$, \\ JOSEPH ANDREWS ${ }^{1}$, SHARON A. VANTYGHEM ${ }^{1}$, D. GEORGE ORMOND ${ }^{1}$, ALISON L. ALLAN ONA $^{1,2,3}$, \\ DAVID I. RODENHISER ${ }^{1,2,4,5}$, ANN F. CHAMBERS ${ }^{1,2,6}$ and ALAN B. TUCK ${ }^{1,2,6}$
}

\author{
${ }^{1}$ London Regional Cancer Program, London Health Sciences Centre; Departments of ${ }^{2}$ Oncology, ${ }^{3}$ Anatomy \& Cell Biology, \\ ${ }^{4}$ Biochemistry, ${ }^{5}$ Paediatrics and ${ }^{6}$ Pathology, University of Western Ontario, London, Ontario, Canada
}

Received March 16, 2009; Accepted May 19, 2009

DOI: 10.3892/ijo_00000340

\begin{abstract}
Although lymphatic dissemination is a major route for breast cancer metastasis, there has been little work to determine what factors control the ability of tumor cells to survive, establish and show progressive growth in a lymph node environment. This information is of particular relevance now, in the era of sentinel lymph node biopsy, where smaller intranodal tumor deposits are being detected earlier in the course of disease, the clinical relevance of which is uncertain. In this study, we compared differentially expressed genes in cell lines of high (468LN) vs. low (468GFP) lymphatic metastatic ability, and related these to clinical literature on genes associated with lymphatic metastatic ability and prognosis, to identify genes of potential clinical relevance. This approach revealed differential expression of a set of genes associated with 'cancer stem cell-like' properties, as well as networks of genes potentially associated with survival and autonomous growth. We explored these differences functionally and found that $468 \mathrm{LN}$ cells have a higher proportion of cells with a cancer stem cell-like (CD44+/CD24-) phenotype, have a higher clonogenic potential and a greater ability to survive, establish and grow in a foreign (lymph node and 3D Matrigel) microenvironment, relative to 468GFP cells. Differentially expressed genes which reflect these functions provide candidates for investigation as potential targets for therapy directed against early lymphatic metastasis.
\end{abstract}

Correspondence to: Dr Alan B. Tuck, Department of Pathology, London Health Sciences Centre, University Hospital, 339 Windermere Rd., London, Ontario N6A 5A5, Canada

E-mail: atuck@uwo.ca

Key words: lymphatic metastasis, breast cancer, gene expression, cancer stem cells, foreign microenvironment

\section{Introduction}

A primary route for metastatic spread of breast carcinoma is via the lymphatic system, and lymph node involvement is arguably the best clinicopathologic prognostic indicator in human breast cancer (1-3). Recent work is beginning to identify mechanisms responsible for the ability of tumor cells to reach lymph nodes, including lymphangiogenesis and various different receptor/chemokine interactions (e.g., CXCR4 and CCR7 interaction with their ligands CXCL12 and CCL21, respectively) (4-6). However, relatively little is known about molecular events that regulate the ability of breast cancer cells to survive, establish and grow in a lymph node environment. In this era of sentinel lymph node biopsy, smaller tumor deposits within lymph nodes are being identified in early stage breast cancer, the clinical significance of which is uncertain (7-12). Although whether lymphatic and hematogenous spread occur in a synchronous or metachronous fashion remains controversial (13), experimental evidence suggests that intranodal tumor deposits can and do act as a source for seeding of downstream sites within the lymph node chain and systemically $(14,15)$. Clinically, involvement of locoregional lymph nodes is often the first indication of propensity for metastatic dissemination $(16,17)$. Thus, understanding mechanisms that control tumor cell behavior within the lymph node environment may reveal potential therapeutic targets at this very early stage of tumor dissemination, critical to the ability of the cells to spread beyond the involved lymph node.

Here we used a pair of human mammary carcinoma cell lines, both derived from MDA-MB-468 cells, one of which is weakly metastatic to lymph nodes (468GFP), the other strongly and widely metastatic to lymph nodes (468LN) (18). We performed gene expression profiling of these cell lines, revealing numerous differences involving several major functional and canonical pathways. To ensure that genes we identified in this manner bore clinical relevance, we compared our profile differences with a dataset we compiled from clinical literature specifically focused on lymphatic 
metastasis (19-21), finding numerous commonalities. Further mining of these expression profile differences yielded gene sets related to stem cell-like properties and those potentially associated with cell survival and autonomous cell growth. In functional assays, both in vitro and in vivo, we show that both cancer stem cell-like properties $\left[\mathrm{CD} 44^{+} / \mathrm{CD} 24^{-}\right.$phenotype (22-25), clonogenicity], and the ability to survive, establish and grow in a $3 \mathrm{D}$ environment are involved in the enhanced lymphatic metastatic ability of 468LN cells. Differentially expressed gene sets between these cell lines are thus both clinically relevant and candidates for investigation as targets for therapy directed against this early stage of metastatic dissemination.

\section{Materials and methods}

Breast cancer cell lines and culture conditions. MDA-MB468 cells (468) were originally isolated from the pleural effusion of a woman with metastatic breast adenocarcinoma (26). The 468GFP subline was generated by stable transfection with pEGFP-C2 (18). The 468LN cell line was isolated from sporadic metastases that arose in lungs after mammary fat pad injection of 468GFP cells in the mammary fat pad, and has a strong metastatic ability to lymph nodes (18). Cells were maintained in $\alpha$-MEM medium (Invitrogen, Burlington, Ontario), with $10 \%$ fetal bovine serum (FBS; Sigma Chemical Company, St. Louis, MO). Both lines were maintained under selective pressure [500 $\mu \mathrm{g} / \mathrm{ml}$ (active) Geneticin; Invitrogen].

\section{In vitro characterization}

Gene expression profile and Ingenuity Pathways Analysis. For expression profiling, cells were grown from frozen stocks as above, but without G418, for 4 passages. At the fifth passage, each cell line was split into three parallel flasks designated biological replicate 1-3 and grown to $\sim 70 \%$ confluence. Total RNA from each biological replicate was isolated using TRIzol (Invitrogen), as per the manufacturer's instructions. RNA $(10 \mu \mathrm{g})$ was used to produce Biotinlabeled cRNA, which was hybridized to Affymetrix HGU133_Plus_2 arrays (Affymetrix, Inc., Santa Clara, CA). Washing, scanning and probe quantification were carried out according to the manufacturer's instructions, using GeneChip Operating Software (www.affymetrix.com), with target intensity set to 150 .

For each array, GCOS output was imported as .txt files into Genespring GX 7.1 software (Agilent), and data were normalized as follows. Values $<0.01$ were set to 0.01 and the median intensity of each array was normalized to the 50th percentile of all arrays. Finally, the intensity of each probe set in each of the three 468LN arrays was divided by the normalized mean intensity of that probe set in the 468GFP arrays. The geometric mean of these 3 ratios is reported.

After normalization, the data were first prefiltered. Any probe set flagged 'absent' by GCOS software in all 6 arrays was removed from further consideration. Next, any remaining probe set not changing at least 2 -fold in 468LN relative to 468GFP was removed. Probe sets passing these criteria were analysed using the one-way ANOVA tool in Genespring, with the nominal $\alpha$-value set at $p<0.05$. The Benjamini and Hochberg multiple testing algorithm of Genespring was used to reduce false discovery rates. The subsequent list of 'significant changers' was divided into significant increasers or decreasers.

Data sets identifying significant changes in gene expression in 468LN vs. 468GFP cells were generated and analyzed with Ingenuity Pathways Analysis (IPA) (Ingenuity ${ }^{\circledR}$ Systems, www.ingenuity.com). Each gene identifier in the data sets was mapped to its corresponding gene in the Ingenuity Pathways Knowledge Base (IPKB), and if present, was considered for analysis. Functional analysis identified biological functions and/or diseases that were most significant to the data set. Canonical pathway analysis identified pathways from the IPA library that were most significant to the data set.

Quantitative real time-PCR ( $q R T-P C R)$ validation. Total RNA was extracted from 3 biological replicates of each cell line using an RNeasy mini kit (Qiagen), and cDNA was synthesized from $1 \mu \mathrm{g}$ total RNA using Superscript II (Invitrogen), with random primers (Invitrogen), as per the manufacturer's instructions. qRT-PCR was performed using a Rotor-Gene RG-3000 (Corbett Research), in combination with SYBR-Green. RT ${ }^{2}$ qPCR primer assays for the selected targets (CDH1, CDK2, DDR1, EGR1, EPHA3, ETV1, IGFBP3, LPXN, MADD, MET, RAB2A, S100A2 and SOX4) and $\mathrm{RT}^{2}$ SYBR-Green qPCR Master Mix were purchased from SuperArray Bioscience Corporation. 18S rRNA was used as an endogeneous control (SuperArray Biosciences Corporation). Fold changes observed in 468LN cells were reported relative to control 468GFP cells.

Flow cytometry analysis - CD44/CD24 marker analysis. Cells were grown to $\sim 80 \%$ confluency and harvested, washed with cold phosphate-buffered saline (PBS) $+2 \%$ FBS and resuspended at $1 \times 10^{6}$ cells $/ \mathrm{ml}$. Cells $\left(1 \times 10^{5}\right)$ were incubated with fluorescent antibodies at $4^{\circ} \mathrm{C}$ for $30 \mathrm{~min}$. Monoclonal anti-human antibodies (BD Biosciences, Mississauga, Ontario) included anti-CD24 (clone ML5) conjugated to phycoerytherin (PE) (orange) and anti-CD44 (clone IM7) conjugated to allophycocyanin (APC, red). IgG isotype controls conjugated to either PE or APC were used as negative controls. Cells were analyzed using a Beckman Coulter FC 500 flow cytometer.

Isolation and preparation of dissociated lymph nodal tissue. Human lymph nodes were obtained from normal subjects (organ donors - approved by University of Western Ontario Human Ethics). Murine lymph nodes were obtained from nude mice (approved by University of Western Ontario Animal Ethics). After all lymph nodes were collected they were transferred into a petri dish with a thin layer of $\alpha$-MEM media. Lymph nodes were gently minced into small pieces with a scalpel and forceps. Media with tissue and cells was transferred into a $40 \mu \mathrm{m}$ cell strainer, connected with a $50 \mathrm{ml}$ conical centrifuge tube. Bigger pieces of tissue debris and connective tissue were strained out and then homogenized with a loose-fitting homogenizer. The single cells and tissue debris $<40 \mu \mathrm{m}$ were collected by centrifugation at $1500 \mathrm{~g}$ for $10 \mathrm{~min}$. Following centrifugation, cell pellets were resuspended in RPMI media (Invitrogen) and cell numbers counted. Cells were seeded in Matrigel, as described below. In some instances the cells were frozen at $-20^{\circ} \mathrm{C}$ for $2 \mathrm{~h}$ and then stored at -80 or $-150^{\circ} \mathrm{C}$ for future use. 


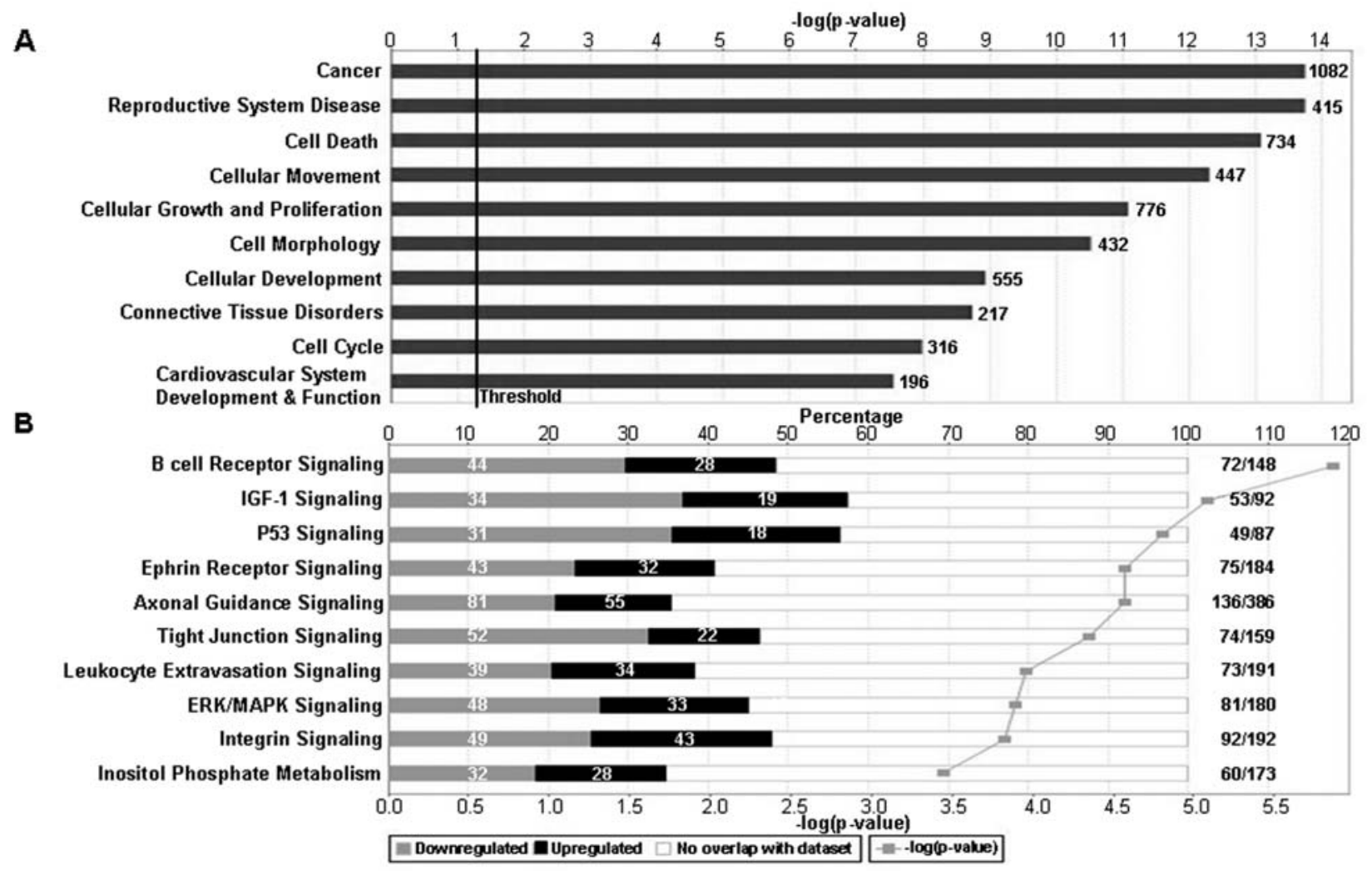

Figure 1. Ingenuity Pathways Analysis of genes differentially expressed (fold change of $\geq 2, \mathrm{p}<0.05$ ) between $468 \mathrm{LN}$ and $468 \mathrm{GFP}$ cell lines. (A) The top 10 functional categories for our dataset based on significance. (B) The top 10 canonical pathways relevant to our dataset based on significance.

Fresh or frozen lymphocytes (mouse or human) were cultured two days prior to co-culture experiments. Lymph nodes $\left(5 \times 10^{5}\right.$ cells/well) were seeded in 6-well plates, in RPMI-1640 10\% heat-inactivated FBS media, and $2 \mathrm{ml}$ of media was added per well. Twenty-four hours later, cell viability was checked by staining a small aliquot from each well with trypan blue and counting viable cells using a hemocytometer. If viable cell numbers were $\geq 90 \%$ of that seeded, these wells were used the following day for coculturing experiments in 3D Matrigel, below.

Matrigel assay. 468GFP and 468LN cells were grown in 3D Matrigel ${ }^{\mathrm{TM}}$ Matrix (BD Biosciences, Oakville, Ontario, Canada), to characterize colony-forming ability and morphology. A basal layer of Matrigel $(10 \mathrm{mg} / \mathrm{ml}, 150 \mu \mathrm{l} / \mathrm{well})$ was first formed in 48-well plates, by allowing warming from 4 to $37^{\circ} \mathrm{C}$ in a $5 \% \mathrm{CO}_{2}$ incubator over $60 \mathrm{~min}$ to solidify. Tumor cells (468GFP or 468LN, 1.0x $10^{4}$ cells per $150 \mu 1$ serum-free media, with $0.1 \% \mathrm{BSA}$ ) were mixed $1: 1$ with another aliquot of Matrigel $\left(10 \mathrm{mg} / \mathrm{ml}\right.$, at $\left.4^{\circ} \mathrm{C}\right)$, modified or not with murine (MLNC) or human (HLNC) lymph nodal cells $\left(4 \times 10^{5} / 1 \times 10^{4}\right.$ tumor cells). Liquid Matrigel and cell mixture (300 $\mu \mathrm{l})$ was then added to the top of each solidified basal Matrigel layer. Each plate was covered and incubated for $60 \mathrm{~min}$ in a $37^{\circ} \mathrm{C}$, $5 \% \mathrm{CO}_{2}$ incubator. Pre-warmed serum-free media $(300 \mu \mathrm{l})$, with $0.1 \% \mathrm{BSA}$, was then added to the top of the solidified Matrigel plugs. Each plate was incubated for 9-15 days at $37^{\circ} \mathrm{C}, 5 \% \mathrm{CO}_{2}$, changing media every other day. Colonies were checked daily and colony counts taken on alternate days. In LNC co-culture experiments, tumor colony morphology was also assessed, in terms of crisply defined spherical colonies, vs. colonies with more irregular, non-spherical profiles. Results were reported as percent non-spherical vs. total number of colonies.

In vivo characterization. Cells were directly injected bilaterally, into right and left inguinal mammary fat pad lymph nodes of female athymic nude $(n u / n u)$ mice (7-8 weeks old, Harlan Laboratory, San Diego, CA). Cells were cultured as above, harvested at $80 \%$ confluence, washed twice by centrifugation with sterile PBS, resuspended at 50,000 cells/50 $\mu \mathrm{l}$ PBS and kept on ice until injection. Cells were injected using a $50 \mu 1$ Hamilton syringe (Hamilton Company, Reno, NV). Following injection, mice were observed for up to 12 weeks.

For all experiments, animals were maintained under specific pathogen-free conditions in micro-isolator cages, with sterilized food and water provided ad libitum. Animals were monitored regularly for evidence of morbidity. Animal care and surgical procedures were conducted in accordance with standards of the Canadian Council on Animal Care, under an approved protocol of the University of Western Ontario Council on Animal Care.

Primary tumor growth was evaluated biweekly, by measurement with calipers in two perpendicular dimensions and tumor volume estimated using the formula [volume $=0.52$ (width) $)^{2}$ (length)], for approximating the volume $\left(\mathrm{mm}^{3}\right)$ of an ellipsoid.

Groups of 5 mice per cell line were sacrificed at $6,8,10$ and 12 weeks post-injection, and injected lymph nodes harvested and formalin-fixed. Tissues were processed, 


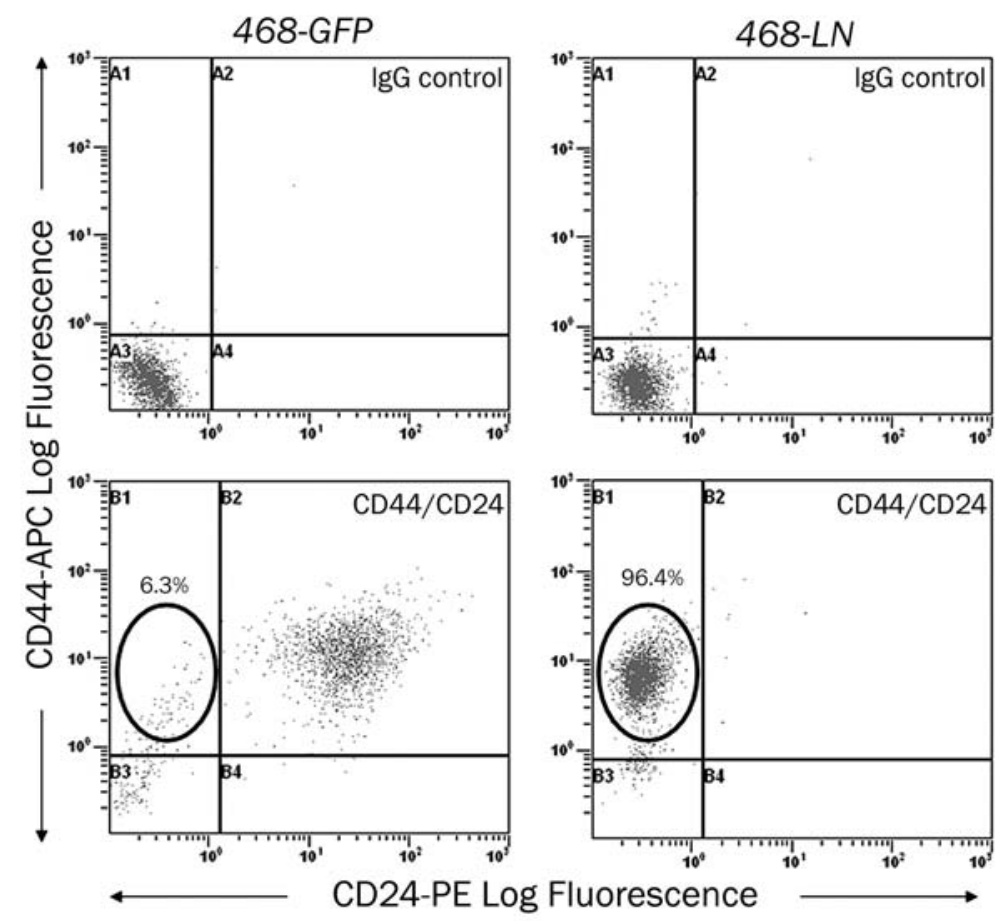

Figure 2. Flow cytometry analysis of CD24/CD44 marker expression in 468GFP and 468LN breast cancer cell lines. Representative histograms demonstrate the expression of CD44-APC (Y-axis) and CD24-PE (X-axis) by 468GFP cells (left panels) and 468LN cells (right panels). Circled regions represent the cells of interest $\left(\mathrm{CD} 44^{+} / \mathrm{CD} 24^{-}\right.$cancer stem cell phenotype).

paraffin-embedded, sectioned and stained with hematoxylin and eosin (H\&E). Histopathologic characteristics and degree of lymph node involvement were assessed by light microscopy. Tumor area was calculated from the slides using the formula: (Pi $\mathrm{x}$ long axis $\mathrm{x}$ short axis)/4.

Statistical analysis. Statistical analyses were performed on the in vitro and in vivo data using Graph Pad Prism (Graph Pad Software Inc., California). Results are expressed as the mean \pm SE. Pair-wise comparisons between means were assessed using Student's t-test. In all cases, p-values of $<0.05$ were regarded as statistically significant.

\section{Results}

Gene expression profiling identified genes differentially expressed. Gene expression profiling by Affymetrix arrays revealed significant differences of $\geq 2$.0-fold (by ANOVA, $\mathrm{p}<0.05$ ) in 6559 genes (up-regulated, 3055; down-regulated, 3504 ) in 468LN vs. 468GFP cells (data series GSE11683, http://www.ncbi.nlm.nih.gov/geo/). Ingenuity Pathway Analysis identified representation of several major functional and canonical categories, with the top ten of each represented in Fig. 1. These include functions associated with cancer in general, cell cycle, cell death, cell movement, cellular growth and proliferation, cell morphology and development, and canonical pathways such as various different receptor signaling pathways (e.g., IGF-1, ephrin and integrin), p53 signaling, ERK/MAPK pathways and inositol phosphate metabolism. To screen for differentially expressed genes with established clinical relevance in lymph node metastasis, we compared 468LN/468GFP differences with a data set that we constructed, comprised of gene lists from reports in the clinical literature examining gene expression profiles/ signatures associated specifically with lymph node metastasis (19-21). In doing so, we found 59 genes that agreed with lists from the literature in terms of relationship of expression with lymphatic metastasis. These differentially expressed (downand up-regulated) genes are shown in Table I. A subset of these genes was validated by qRT-PCR (Table I).

Interestingly, it was noticed that 468LN cells have reduced expression of CD24 RNA compared to 468GFP cells, and that a number of other gene expression profile differences fell into functional categories which might suggest cancer stem cell-like properties (i.e., transcriptional regulators, signal transduction pathways, regulation of cell growth and proliferation). Comparisons with a data set we constructed, comprised of gene lists from the literature on expression profiles/signatures of breast cancer cells with stem cell-like properties $(23,27,28)$, revealed 61 genes differentially expressed between $468 \mathrm{LN}$ and $468 \mathrm{GFP}$ cells that were represented on the data set of cancer stem cell-like gene expression profiles/signatures (Table II). In addition to these gene expression differences, we observed alterations in expression of several Wnt, Notch and TGF- $\beta$ pathway genes [e.g., dishevelled homolog 1 (up 2.3-fold), Notch 4 (up 2.2fold) and SMAD4 (up 40.1-fold)], more traditionally associated with the stem cell phenotype in experimental systems (29). As this information suggested a preponderance of stem cell-like cells in the $468 \mathrm{LN}$ population, we characterized CD44/CD24 protein expression of both cell lines by flow cytometry. 
Table I. The down-regulated and up-regulated genes common to the clinical lymphatic metastasis data set (data series GSE11683, http://www.ncbi.nlm.nih.gov/geo/).

A, Down-regulated genes.

\begin{tabular}{|c|c|c|c|c|}
\hline \multirow[b]{2}{*}{ Gene symbol } & \multirow[b]{2}{*}{ Gene name } & \multirow[b]{2}{*}{ Function } & \multicolumn{2}{|c|}{ Fold change } \\
\hline & & & Array & qRTPCR \\
\hline ADAR & Adenosine deaminase, RNA-specific & dsRNA binding & -1.16 & \\
\hline ALDH1A3 & $\begin{array}{l}\text { Aldehyde dehydrogenase } 1 \text { family, } \\
\text { member A3 }\end{array}$ & Retinoic acid biosynthesis & -100.00 & \\
\hline ANXA1 & Annexin A1 & Protein binding, cell motility & -3.03 & \\
\hline CCND1 & Cyclin D1 & Cell cycle & -6.82 & \\
\hline CDH1 & E-cadherin & Cell adhesion & -100.00 & -100.00 \\
\hline COL5A2 & Collagen type $\mathrm{V}, \alpha 2$ & Extracellular matrix & -10.28 & \\
\hline CORO1A & Coronin, actin binding protein $1 \mathrm{~A}$ & Cell motility, cellular structure & -27.44 & \\
\hline CTDSPL & CTD small phosphatase-like protein & Proliferation, differentiation & -6.05 & \\
\hline CTGF & Connective tissue growth factor & $\begin{array}{l}\text { Proliferation, cell adhesion, } \\
\text { differentiation }\end{array}$ & -3.57 & \\
\hline DDR 1 & $\begin{array}{l}\text { Discoidin domain receptor family, } \\
\text { member } 1\end{array}$ & Cell adhesion & -100.00 & -100.00 \\
\hline EGR1 & Early growth response 1 & Regulation of transcription & -10.01 & -20.41 \\
\hline F8 & Coagulation factor VIII & Cell adhesion, coagulation & -4.35 & \\
\hline FBLN1 & Fibulin 1 & $\begin{array}{l}\text { Cell adhesion, migration, } \\
\text { tumor suppressor }\end{array}$ & -16.67 & \\
\hline FN1 & Fibronectin 1 & Cell adhesion & -19.95 & \\
\hline GSTZ1 & Glutathione transferase $\zeta 1$ & Amino acid metabolism & -1.74 & \\
\hline IFITM3 & Inteferon-induced transmembrane protein 3 & Immune response & -3.71 & \\
\hline IGFBP3 & Insulin-like growth factor binding protein 3 & $\begin{array}{l}\text { Signal transduction, proliferation, } \\
\text { apoptosis }\end{array}$ & -100.00 & -100.00 \\
\hline ITGBL1 & Integrin $B$-like 1 & Cell adhesion, signal transduction & -6.07 & \\
\hline KRT6B & Keratin 6B & Cellular structure & -25.00 & \\
\hline KRT14 & Keratin 14 & Cellular structure & -100.00 & \\
\hline KRT17 & Keratin 17 & Cellular structure & -100.00 & \\
\hline MADD & MAP-kinase activating death domain & Apoptosis, cell cycle & -2.20 & -1.76 \\
\hline MGP & Matrix Gla protein & Ossification & -6.67 & \\
\hline MME & Membrane metallo-endopeptidase & Metallopeptidase activity & -50.00 & \\
\hline OLFML3 & Olfactomedin-like 3 & Extracellular matrix & -50.00 & \\
\hline PDK4 & Pyruvate dehydrogenase kinase 4 & Regulation of metabolism & -6.48 & \\
\hline PLS3 & Plastin 3 (T isoform) & Actin binding & -1.47 & \\
\hline PLXDC2 & Plexin domain containing 2 & Angiogenesis, cell adhesion & -8.33 & \\
\hline RPL31 & Ribosomal protein L31 & RNA binding, translation & -1.76 & \\
\hline S100A2 & S100 calcium binding protein A2 & Tumor suppressor & -16.67 & -14.29 \\
\hline SC4MOL & Sterol-C4-methyl oxidase-like & Cholesterol biosynthesis & -2.09 & \\
\hline SDC1 & Syndecan 1 & Cytoskeletal protein binding & -9.09 & \\
\hline SERPINB5 & $\begin{array}{l}\text { Serpin peptidase inhibitor, clade B } \\
\text { (ovalbumin), member } 5\end{array}$ & Tumor suppressor & -33.33 & \\
\hline SOX4 & SRY (sex determining region Y)- box 4 & Regulation of transcription & -4.06 & -5.75 \\
\hline TAGLN & Transgelin & Actin binding & -50.00 & \\
\hline TCEA2 & Transcription elongation factor A, 2 & Regulation of transcription & -4.69 & \\
\hline TIMP3 & Tissue inhibitor of metalloproteinase 3 & Enzyme inhibitor & -1.56 & \\
\hline TM4SF1 & Transmembrane $4 \mathrm{~L}$ six family member 1 & Cell surface marker & -7.10 & \\
\hline
\end{tabular}

Genes down-regulated in both the clinical lymphatic metastasis data set and 468LN vs. 468GFP cells. ${ }^{\text {a }}$ 
B, Up-regulated genes.

Fold change

\begin{tabular}{|c|c|c|c|c|}
\hline \multirow{2}{*}{ Gene symbol } & \multirow[b]{2}{*}{ Gene name } & \multirow[b]{2}{*}{ Function } & \\
\hline & & & Array & qRTPCR \\
\hline CD83 & CD83 molecule & Signal transduction & 2.74 & \\
\hline CDK2 & Cyclin-dependent kinase 2 & Cell cycle & 7.81 & 2.59 \\
\hline CSK & c-src tyrosine kinase & Signal transduction & 1.80 & \\
\hline EPHA3 & EPH receptor A3 & Protein binding & 471.97 & 246.96 \\
\hline ERCC1 & Excision repair cross complementing 1 & DNA repair & 1.96 & \\
\hline ETS1 & $\begin{array}{l}\text { Avian erythroblastosis virus E26 (v-ets) } \\
\text { oncogene homolog-1 }\end{array}$ & Regulation of transcription & 3.78 & \\
\hline ETV1 & Ets variant gene 1 & Regulation of transcription & 2.56 & 6.25 \\
\hline GLS & Glutaminase & Glutamate metabolism & 3.41 & \\
\hline IRF2 & Interferon regulatory factor 2 & Regulation of transcription & 1.88 & \\
\hline LPXN & Leupaxin & $\begin{array}{l}\text { Signal transduction, } \\
\text { cell adhesion }\end{array}$ & 28.48 & 76.76 \\
\hline MET & Hepatocyte growth factor receptor & Signal transduction & 2.71 & 3.56 \\
\hline NDUFA5 & $\begin{array}{l}\text { NADH dehydrogenase (ubiquinone) } 1 \alpha \\
\text { subcomplex } 5\end{array}$ & Electron transport & 2.61 & \\
\hline PAM & $\begin{array}{l}\text { Peptidylglycine } \alpha \text {-amidating } \\
\text { monooxygenase }\end{array}$ & Protein modification & 1.86 & \\
\hline PEX12 & Peroxisomal biogenesis factor 12 & Protein binding & 1.65 & \\
\hline PHLDA1 & $\begin{array}{l}\text { Pleckstrin homology-like domain, } \\
\text { family A member } 1\end{array}$ & Apoptosis & 1.48 & \\
\hline RAB2 & Ras-related protein Rab-2A & Protein transport & 4.08 & 2.03 \\
\hline RAPGEF6 & Rap guanine nucleotide exchange factor (GEF) 6 & Signal transduction & 2.53 & \\
\hline RFX5 & Regulatory factor X, 5 & Regulation of transcription & 1.76 & \\
\hline SCAMP2 & Secretory carrier membrane protein 2 & Protein transport & 1.89 & \\
\hline SIAT1 & $\begin{array}{l}\text { Sialyltransferase } 1 \\
\text { (ß-galactoside } \alpha \text {-2,6-sialyltransferase) }\end{array}$ & Protein modification & 4.45 & \\
\hline TOSO & Fas apoptotic inhibitory molecule 3 & Anti-apoptosis & 8.80 & \\
\hline
\end{tabular}

Genes up-regulated in both the clinical lymphatic metastasis data set and 468LN vs. 468GFP cells. ${ }^{\text {a }}$ uanitative real-time PCR (qRTPCR) validation of selected genes was performed and their corresponding fold change values are listed. Clinical lymphatic metastasis data set generated from combined gene lists (17-19).

Finally, Ingenuity Analysis of gene expression profile differences between 468GFP and 468LN cells also revealed that the top five most relevant networks represented involved functional categories potentially associated with cell survival and autonomous growth ability in a foreign environment (i.e., categories of cancer, cell death, cell cycle, cell growth and proliferation, DNA replication, recombination and repair, RNA damage and repair).

Flow cytometry. CD44/CD24 protein expression was examined by flow cytometry of single cell suspensions of both cell lines. A minority $(6.3 \pm 1.9 \%)$ of $468 \mathrm{GFP}$ cells were CD44+/CD24- (Fig. 2), consistent with data previously reported, where $3 \%$ of MDA-MB-468 cells had a CD44+/ CD24- phenotype (30). In contrast, the vast majority $(96.4 \pm 1.1 \%)$ of $468 \mathrm{LN}$ cells were $\mathrm{CD}^{4} 4^{+} / \mathrm{CD} 24-$, suggesting a high proportion of cancer stem cell-like cells in the $468 \mathrm{LN}$ population.

Morphology and growth characteristics of 468 GFP and $468 \mathrm{LN}$ in vitro. Based on these microarray and flow cytometry findings, which showed that the two cell lines differ both in proportion of cancer stem cell-like cells and expression of genes associated with growth in a lymph node environment, we compared the in vitro morphology and growth characteristics of $468 \mathrm{GFP}$ and $468 \mathrm{LN}$ cells, when grown in 3D Matrigel, with or without MLNC or HLNC (Fig. 3). The colony-forming ability of 468LN cells was found to be $\sim 3$-fold greater than that of $468 \mathrm{GFP}$ cells, both in unmodified Matrigel and in Matrigel with MLNC added $(\mathrm{p}<0.005$ for both) (Fig. 3A). Interestingly, rather than inhibiting colony formation, addition of MLNC to Matrigel 
Table II. The down-regulated and up-regulated genes common to the breast cancer stem cell-like data set (data series GSE11683, http://www.ncbi.nlm.nih.gov/geo/).

A, Down-regulated genes.

\begin{tabular}{|c|c|c|}
\hline Gene symbol & Gene name & Fold change \\
\hline AIM1 & Absent in melanoma 1 & -3.9 \\
\hline ANK3 & Ankyrin 3, node of Ranvier (ankyrin G) & -2.2 to -2.8 \\
\hline AZGP1 & $\alpha$-2-glycoprotein 1 , zinc & -30.7 \\
\hline B7-H4 & Immune costimulatory protein B7-H4 & -35.2 \\
\hline $\mathrm{CD} 24$ & CD24 antigen & -95.4 to -100 \\
\hline CD59 & CD59 antigen p18-20 & -2.8 \\
\hline CITED4 & $\mathrm{Cbp} / \mathrm{p} 300$-interacting transactivator & -10.3 \\
\hline CLDN7 & $\mathrm{GABA}(\mathrm{A})$ receptor-associated protein & -99.7 \\
\hline CYP4V2 & Hypothetical protein LOC285440 & -11.3 \\
\hline ELF3 & E74-like factor 3 & -12.3 to -22.6 \\
\hline ELL2 & Elongation factor, RNA polymerase II, 2 & -4.3 \\
\hline $\begin{array}{l}\text { EMP1 } \\
\text { FGFR2 }\end{array}$ & $\begin{array}{l}\text { Epithelial membrane protein } 1 \\
\text { Fibroblast growth factor receptor } 2\end{array}$ & $\begin{array}{l}-2.3 \\
-6.3\end{array}$ \\
\hline FLJ10948 & Hypothetical protein FLJ10948 & -9.3 \\
\hline FLNB & Filamin $\mathrm{B}, ß$ (actin binding protein 278 ) & -2.5 \\
\hline GABARAPL1 & GABA(A) receptors associated protein-like 3 & -3.5 \\
\hline GJE1 & Homo sapiens PAC clone RP4-604G5 & -20.8 \\
\hline HNMT & Histamine N-methyltransferase & -5.9 \\
\hline IER5 & Immediate early response 5 & -10.7 \\
\hline IRF1 & Interferon regulatory factor 1 & -2.2 \\
\hline IRX3 & Iroquois homeobox protein 3 & -11.7 \\
\hline KIAA0792 & KIAA0792 gene product & -5.2 \\
\hline KRT17 & Homo sapiens gene for cytokeratin 17. & -59.8 to -100 \\
\hline KRT18 & Keratin 18 & -8.4 \\
\hline LOC130576 & Hypothetical protein LOC130576 & -13.4 \\
\hline LTA4H & Leukotriene A4 hydrolase & -2.2 \\
\hline $\mathrm{MCP}$ & Membrane cofactor protein & -2.7 \\
\hline MGC45840 & Hypothetical protein MGC45840 & -9.8 \\
\hline MGP & Matrix Gla protein & -6.5 \\
\hline MIR & c-mir, cellular modulator of immune recognition & -6.3 \\
\hline MLF1 & Myeloid leukemia factor 1 & -2.1 \\
\hline NPD014 & Hypothetical protein dJ465N24.2.1 & -2.3 \\
\hline PRSS16 & Protease, serine, 16 (thymus) & -59.0 \\
\hline SERTAD1 & SERTA domain containing 1 & -2.2 \\
\hline SFPQ & Splicing factor proline/glutamine rich & -305.0 \\
\hline SH3YL1 & SH3 domain containing, Ysc84-like 1 & -16.8 \\
\hline STC2 & Stanniocalcin 2 & -25.8 \\
\hline
\end{tabular}


Table IIA. Continued.

\begin{tabular}{llc}
\hline Gene symbol & Gene name & Fold change \\
\hline TMC4 & Transmembrane channel-like 4 & -3.4 \\
VIL2 & Villin 2 (ezrin) & -22.4 \\
VMP1 & Rat vacuole membrane protein 1 & -5.2 \\
Est & LOC388279 (LOC388279), mRNA & -2.9 \\
Est & Similar to rodent testis enriched hsp70 kDa family member & -5.1 \\
Est & Highly similar to homo sapiens CD24 signal transducer mRNA & -80.4 \\
\hline
\end{tabular}

Genes down-regulated in both the stem cell-like cells from the literature data set and 468LN vs. 468GFP. ${ }^{a}$

B, Up-regulated genes.

\begin{tabular}{|c|c|c|}
\hline Gene symbol & Gene name & Fold change \\
\hline ANXA5 & Annexin A5 & 2.3 \\
\hline ARF3 & ADP-ribosylation factor 3 & 2.2 \\
\hline C16orf33 & Chromosome 16 open reading frame 33 & 2.3 \\
\hline C1R & Complement component $1, \mathrm{r}$ subcomponent & 2.0 \\
\hline FLJ10587 & Hypothetical protein FLJ10587 & 6.0 \\
\hline GNPDA1 & Glucosamine-6-phosphate deaminase 1 & 2.6 \\
\hline HSPG2 & Heparan sulfate proteoglycan 2 (perlecan) & 9.8 to 16.7 \\
\hline ID3 & Inhibitor of DNA binding 3 & 2.1 \\
\hline IGFBP7 & Insulin-like growth factor binding protein 7 & 27.9 to 153.4 \\
\hline KIAA1600 & KIAA1600 & 4.1 \\
\hline LPIN2 & Lipin 2 & 4.7 \\
\hline MMP14 & cDNA clone NT2RM4002036 3', mRNA sequence. & 7.8 \\
\hline MYO10 & Myosin X & 2.4 to 4.0 \\
\hline PAK2 & p21 (CDKN1A)-activated kinase 2 & 6.2 \\
\hline PDE8A & Phosphodiesterase $8 \mathrm{~A}$ & 2.0 \\
\hline PFKFB3 & 6-phosphofructo-2-kinase/fructose-2,6-biphosphatase 3 & 3.4 \\
\hline SPARC & Secreted protein, acidic, cysteine-rich (osteonectin) & 18.43 to 554.0 \\
\hline SPP1 & Secreted phosphoprotein 1 (Osteopontin) & 11.6 \\
\hline STAM & Signal transducing adaptor molecule 1 & 3.42 \\
\hline VIM & Vimentin & 10.8 to 103.7 \\
\hline XPNPEP1 & Homo sapiens $\mathrm{X}$-prolyl aminopeptidase 1 & 2.76 \\
\hline
\end{tabular}

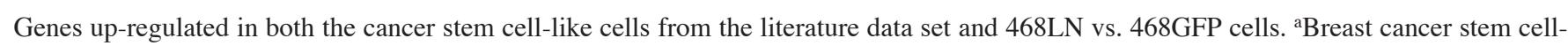
like data set generated from combined gene lists $(21,25,26)$.

resulted in a significant increase in both 468GFP and 468LN colonies $(\mathrm{p}<0.005)$ (Fig. 3A). In lymph node modified Matrigel, comparable results were obtained whether human or mouse lymph nodal tissue was used (Fig. 3B), allowing us to use mouse lymph nodal tissue for most co-culture assays.
Colony morphology also differed between 468GFP and 468LN in 3D culture. 468LN colonies were more nonspherical/dispersed than 468GFP colonies, independent of the presence of lymph node tissue (Fig. 3C and D). A higher proportion of non-spherical 468GFP colonies was seen on 
A
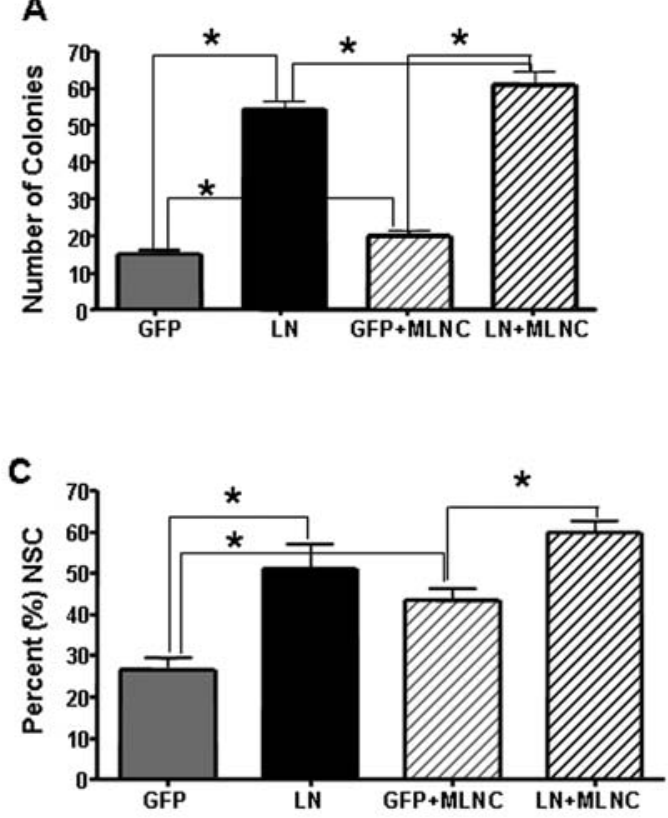

B
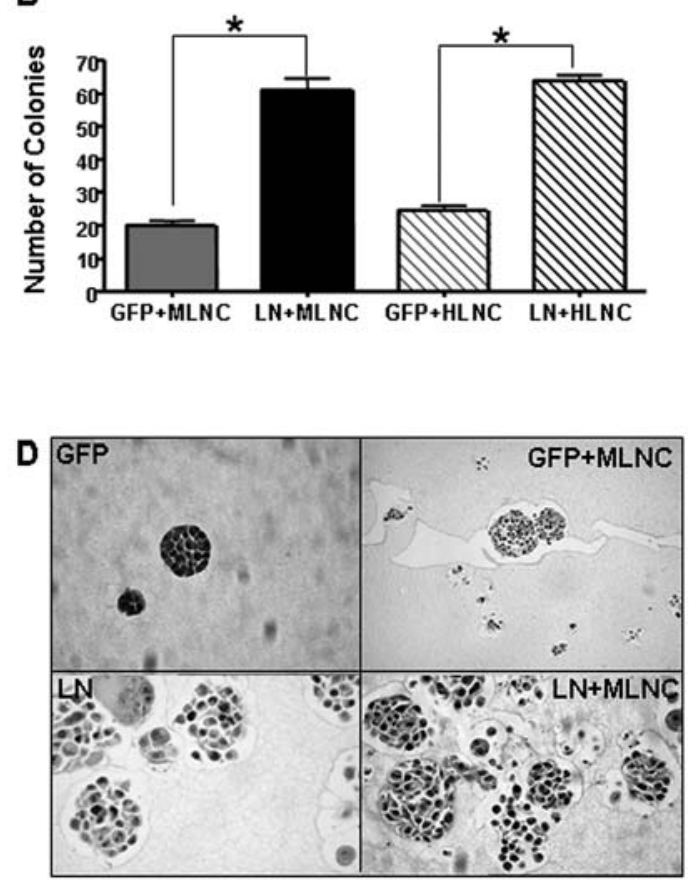

Figure 3. (A) In vitro colony-forming ability of 468GFP (GFP) vs. 468LN (LN) cells, in 3D Matrigel (15 day) with and without lymph node tissue from female nude mice (MLNC). ("p<0.005 for all-paired comparisons). (B) In vitro colony-forming ability of 468GFP (GFP) vs. 468LN (LN) cells at day 15, when grown in 3D Matrigel with lymph node tissue from female nude mice (MLNC) or human lymph node (HLNC) ( ${ }^{*} \mathrm{p}<0.005$ for all-paired comparisons). (C) In vitro colony morphology [\% non-spherical colonies (NSC)] for 468GFP (GFP) vs. 468LN (LN) cells, when grown in 3D Matrigel (15 day), with and without lymph node tissue from female nude mice (MLNC) [ ${ }^{*} \mathrm{p}<0.005$ for all-paired comparisons]. (D) Top left and top right panels, colony morphology of 468GFP (GFP) in Matrigel alone and with MLNC (15 day). Bottom left and bottom right panels, 468LN (LN) in Matrigel alone and with MLNC (15 day). H\&E; magnification, $\mathrm{x} 20$.

addition of MLNC, although still significantly less than in cultures of 468LN ( $<<0.005)$.

Growth characteristics of $468 G F P$ and $468 L N$ in vivo. To characterize tumor cell behavior in vivo, 468GFP and 468LN cells were injected directly into right and left inguinal lymph nodes of female nude mice and various aspects of intranodal tumor growth were assessed. 468LN lymph node tumors were palpable by $4-6$ weeks and tumor take was $100 \%$ of injected nodes at 10 weeks post-injection. In contrast, tumor take for the 468 GFP cells was only 30 and $20 \%$ of injected nodes at 10 and 12 weeks, respectively. 468LN tumors had a shorter latency period, taking only 8 to 10 weeks to reach a mean tumor volume of $\sim 500 \mathrm{~mm}^{3}$, compared to $468 \mathrm{GFP}$, which did not reach that size even at the 12 -week endpoint (Table III).

Histological investigation confirmed 70 and $80 \%$ of 468GFP cell-injected nodes were negative at 10 and 12 weeks respectively, and $100 \%$ of $468 \mathrm{LN}$ nodes positive at 10 weeks (e.g., Fig. 4A and D). Where tumor take was evident, intranodal deposits of neoplastic cells were confirmed, with involved lymph nodes showing the destruction of nodal architecture (Fig. 4C and D). At later time points, there was associated extranodal extension of tumor into adjacent adipose tissue (particularly for 468LN). Mean tumor sizes of 468LN at weeks 10 and 12 were $52.9 \pm 27$ and $78.2 \pm 19.2 \mathrm{~mm}^{2}$, respectively, whereas corresponding sizes for 468GFP tumors were $36.4 \pm 3.0$ and $48.7 \pm 8.9 \mathrm{~mm}^{2}$, respectively (Table III).
Overall, 468LN tumors showed enhanced growth relative to the 468GFP tumors, producing significantly larger tumor volumes from week 6 through to week $12(\mathrm{p}<0.05)$ (Table III).

\section{Discussion}

It has been argued that metastatic dissemination is a relatively early event in breast cancer progression (13) and that whether or not a patient develops metastasis is dependent on seed/soil phenomena which control growth of tumor cells in the new microenvironment $(8,31,32)$. As propensity for metastasis is often first indicated clinically by positive locoregional lymph nodes (in the absence of clinically detectable distant metastases), seeding of lymph nodes in particular may occur quite early in the course of disease. If lymph node metastases represent a reservoir for further lymphatic and later visceral dissemination $(14,15,17)$, then an understanding of what controls the ability of carcinoma cells that reach the lymph node to survive, establish and grow in this foreign environment may be critical to an understanding of lymphatic metastasis. However, there are very few studies in the literature that address this question.

Here we have used a pair of related cell lines derived from MDA-MB-468 cells. One of these derivative lines (468LN) is highly metastatic via a lymphatic route, compared with the very weakly metastatic parental cell line (468GFP) (18). Our gene expression profiling of these two lines revealed numerous differences, which fell into broad, biologically 
A
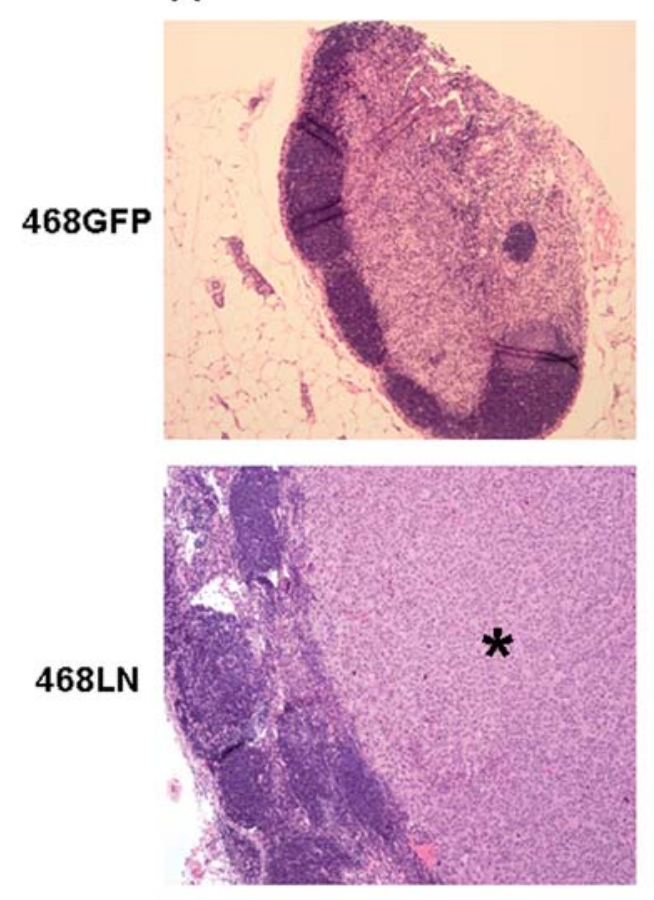

C
B
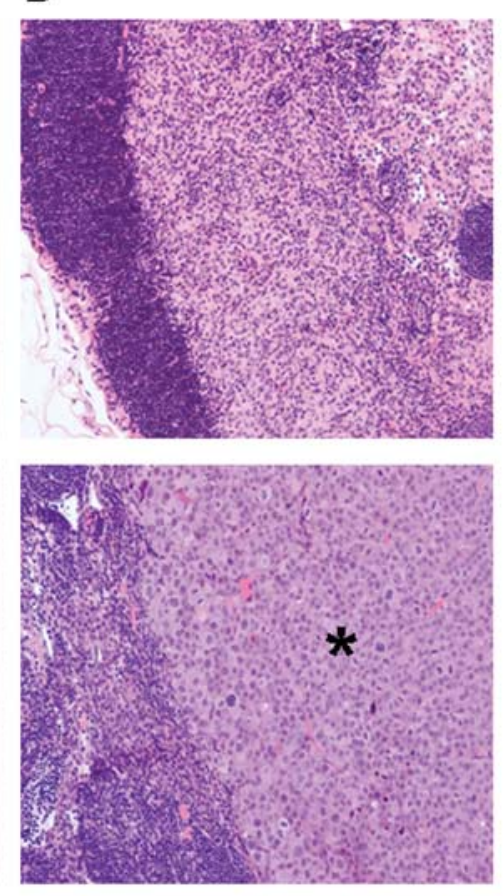

D

Figure 4. In vivo histomorphology of mammary fat pad lymph nodes 6 weeks post direct intranodal inoculation of cells. (A and B) Lymph node injected at time 0 with 468GFP cells. Reactive changes (sinus histiocytosis) are seen, but no involvement by tumor (H\&E, 100x and 400x respectively). (C and D) Lymph node injected at time 0 with $468 \mathrm{LN}$ cells. There is lymph node enlargement, with regional involvement by tumor (*) and resulting effacement of normal architecture (H\&E; magnification, x100 and x400, respectively).

Table III. In vivo growth ability of 468LN vs. 468GFP cells, 6-12 weeks after direct injection bilaterally into inguinal lymph nodes of female nude mice.

\begin{tabular}{|c|c|c|c|c|c|}
\hline Weeks post injection & Mice no. & Mice with tumors & Tumor no. & $\begin{array}{c}\text { Tumor volume } \\
(\text { Calipers })^{\mathrm{a}} \\
\text { Mean } \pm \mathrm{SD}\left(\mathrm{mm}^{3}\right) \times 10^{2}\end{array}$ & $\begin{array}{c}\text { Tumor area } \\
(\text { Histology })^{\mathrm{a}} \\
\text { Mean } \pm \mathrm{SD}\left(\mathrm{mm}^{2}\right)\end{array}$ \\
\hline & \multicolumn{3}{|c|}{ MDA MB 468-GFP } & & \\
\hline 6 & 5 & 0 & 0 & - & 0.0 \\
\hline 8 & 5 & 0 & 0 & - & 0.0 \\
\hline 10 & 5 & 3 & 3 & $1.3 \pm 2.0$ & $36.4 \pm 3.0$ \\
\hline \multirow[t]{2}{*}{12} & 5 & 2 & 2 & $1.0 \pm 2.0$ & $48.7 \pm 8.9$ \\
\hline & \multicolumn{3}{|c|}{ MDA MB 468-LN } & & \\
\hline 6 & 5 & 5 & 6 & $2.0 \pm 1.3$ & $13.2 \pm 1.3$ \\
\hline 8 & 5 & 5 & 7 & $3.0 \pm 2.0$ & $26.8 \pm 17.6$ \\
\hline 10 & 5 & 5 & 10 & $7.4 \pm 4.4$ & $52.9 \pm 27.0$ \\
\hline 12 & 5 & 5 & 6 & $5.0 \pm 4.0$ & $78.2 \pm 19.2$ \\
\hline
\end{tabular}

${ }^{\mathrm{a}} \mathrm{p}<0.05$ for $468 \mathrm{GFP}$ vs. $468 \mathrm{LN}$ for all the time points; -, non-palpable.

relevant functional categories and canonical pathways. To establish potential clinical relevance of these differences, we compared our database (genes up- or down-regulated between 468 LN and 468GFP) with literature involving clinical specimens that focused specifically on gene expression profiles associated with lymphatic metastasis (19-21). In doing so, we found 59 genes in common out of 297 genes from the clinical literature, indicating that this model reflects differential gene expression patterns found in clinical specimens in human patients.

Clues from gene expression profiles of 468LN and $468 \mathrm{GFP}$ also indicated possible cancer stem cell-like 
properties of the 468LN cells, leading us to compare these profiles with existing literature on stem cell-like gene signature patterns in clinical specimens $(23,27,28)$. We then tested the hypothesis that $468 \mathrm{LN}$ cells had greater proportion of cancer stem cells by flow cytometry analysis of two markers of breast cancer stem cells $\left(\mathrm{CD} 44^{+} / \mathrm{CD} 24^{-}\right)$. We found that a very high proportion $(96.4 \%)$ of $468 \mathrm{LN}$ cells were $\mathrm{CD} 44^{+} / \mathrm{CD} 24$, compared to only a small minority of 468GFP cells with this phenotype. Although the concept of cancer stem cells has been controversial, growing literature suggests that a subpopulation of $\mathrm{CD} 44^{+} / \mathrm{CD} 24$ - breast cancer cells is responsible for the self-renewing properties and malignant behavior of human breast tumors $(24,25,30,33$ $36)$. These putative cancer stem cells have been reported to constitute $12-60 \%$ of the tumor cells in clinical breast cancer specimens (23). Similarly, work using established human breast cancer cell lines has shown that more malignant cell lines (e.g., MDA-MB-231, MDA-MB-436, Hs578T, SUM1315 and HBL-100) generally contain a higher proportion $\left(>30 \%\right.$ ) of $\mathrm{CD} 44^{+} / \mathrm{CD} 24-$ cells $(30)$. In our study, we found that $468 \mathrm{LN}$ shows a markedly higher proportion of CD44+CD24- cells than 468GFP, so we asked whether this characteristic translated to increased colony-forming ability in $3 \mathrm{D}$, as one might expect of a population with a high proportion of stem cell-like cells. We indeed found significantly better colony formation and a higher proportion of dispersed colony profiles for 468LN cells, in 3D Matrigel, either in the presence or absence of lymph nodal tissue.

In addition, our microarray data mining indicated that the top five most relevant networks represented involved functional categories potentially associated with cell survival and autonomous growth ability in a foreign environment. Consistent with this, our in vitro assays in Matrigel showed that the colony-forming ability of the highly metastatic 468LN cells was much greater than that of 468GFP cells. Interestingly, the addition of viable lymph nodal tissue (mouse or human) to the system enhanced, rather than inhibited the growth of both cell lines, with 468LN cells again out-performing 468GFP. This would suggest that there is an inherent ability of 468LN cells to survive and show autonomous growth, and that there are in addition factors present in the lymph node environment that promote this phenomenon. Similarly, when cells were inoculated directly into inguinal lymph nodes of mice, $468 \mathrm{LN}$ cells showed significantly better tumor take, with more rapid tumor growth, to a larger maximum size. This system thus gives evidence that both the proportion of cancer stem cell-like cells and the ability to survive and show autonomous growth in a foreign microenvironment are involved in the differential lymphatic metastatic ability of these two cell lines.

The data presented here fit well with the concept that both the presence and properties of purported cancer stem cells and the microenvironment or niche in which they are located, are important in determining tumor growth and invasion in a foreign environment, such as the lymph node $(37,38)$. We describe a system that can specifically address the issue of differential tumor cell growth in a lymph node environment, and have used it to identify differentially expressed genes of potential clinical relevance. The next step will be to determine which of these changes are critical to the ability of tumor cells to survive, establish and grow in a lymph node environment, and hence provide insight into possible therapeutic approaches to block this early stage of the metastatic process.

\section{Acknowledgements}

We would like to thank Dr Pieter Anborgh and Dr Brigitte Goulet for their help in editing the manuscript. This research is funded by grant no. 016506 from the Canadian Breast Cancer Research Alliance 'Special Competition in New Approaches to Metastatic Diseases', with special funding from the Canadian Breast Cancer Foundation and The Cancer Research Society (to AFC, ABT, ALA and DIR), and by a grant from the London Regional Cancer Program (to ALA). ALA receives salary support from the Imperial Oil Foundation and AFC receives salary support from the Canada Research Chairs Program. The microarray data, array profile comparisons and Ingenuity Analysis summary information discussed in this publication have been deposited in the National Center for Biotechnology Information's Gene Expression Omnibus (GEO) under accession GSE11683.

\section{References}

1. McGuire WL: Prognostic factors for recurrence and survival in human breast cancer. Breast Cancer Res Treat 10: 5-9, 1987.

2. Carter CL, Allen C and Henson DE: Relation of tumor size, lymph node status, and survival in 24,740 breast cancer cases. Cancer 63: 181-187, 1989.

3. Nemoto T, Vana J, Bedwani RN, Baker HW, McGregor FH and Murphy GP: Management and survival of female breast cancer: Results of a national survey by the American College of Surgeons. Cancer 45: 2917-2924, 1980.

4. Nathanson SD: Insights into the mechanisms of lymph node metastasis. Cancer 98: 413-423, 2003.

5. Nathanson SD: Preclinical models of regional lymph node tumor metastasis. Cancer Treat Res 135: 129-156, 2007.

6. Eccles S, Paon L and Sleeman J: Lymphatic metastasis in breast cancer: importance and new insights into cellular and molecular mechanisms. Clin Exp Metastasis 24: 619-636, 2007.

7. Dowlatshahi K, Fan M, Snider HC and Habib FA: Lymph node micrometastases from breast carcinoma: reviewing the dilemma. Cancer 80: 1188-1197, 1997.

8. Page DL, Anderson TJ and Carter BA: Minimal solid tumor involvement of regional and distant sites: When is a metastasis not a metastasis? Cancer 86: 2589-2592, 1999.

9. Rampaul RS, Miremadi A, Pinder SE, Lee A and Ellis IO: Pathological validation and significance of micrometastasis in sentinel nodes in primary breast cancer. Breast Cancer Res 3: 113-116, 2001.

10. Hermanek P, Hutter RV, Sobin LH and Wittekind C: International Union Against Cancer. Classification of isolated tumor cells and micrometastasis. Cancer 86: 2668-2673, 1999.

11. Querzoli P, Pedriali M, Rinaldi R, Lombardi AR, Biganzoli E, Boracchi P, Ferretti S, Frasson C, Zanella C, Ghisellini S, Ambrogi F, Antolini L, Piantelli M, Iacobelli S, Marubini E, Alberti $\mathrm{S}$ and Nenci I: Axillary lymph node nanometastases are prognostic factors for disease-free survival and metastatic relapse in breast cancer patients. Clin Cancer Res 12: 6696-6701, 2006.

12. Rutgers EJ: Sentinel node biopsy: interpretation and management of patients with immunohistochemistry-positive sentinel nodes and those with micrometastases. J Clin Oncol 26: 698-702, 2008.

13. Pantel $\mathrm{K}$ and Brakenhoff RH: Dissecting the metastatic cascade. Nat Rev Cancer 4: 448-456, 2004.

14. Ward PM and Weiss L: The relationship between lymphogenous and hematogenous metastasis in rats bearing the MT-100-TC mammary carcinoma. Clin Exp Metastasis 7: 253-264, 1989.

15. Ward PM and Weiss L: Metachronous seeding of lymph node metastases in rats bearing the MT-100-TC mammary carcinoma: the effect of elective lymph node dissection. Breast Cancer Res Treat 14: 315-320, 1989. 
16. Tobler NE and Detmar M: Tumor and lymph node lymphangiogenesis - impact on cancer metastasis. J Leukoc Biol 80: 691-696, 2006.

17. Sleeman JP: The lymph node as a bridgehead in the metastatic dissemination of tumors. Recent Results Cancer Res 157: 55-81, 2000 .

18. Vantyghem SA, Allan AL, Postenka CO, Al-Katib W, Keeney M, Tuck AB and Chambers AF: A new model for lymphatic metastasis: development of a variant of the MDA-MB-468 human breast cancer cell line that aggressively metastasizes to lymph nodes. Clin Exp Metastasis 22: 351-361, 2005.

19. Feng Y, Sun B, Li X, Zhang L, Niu Y, Xiao C, Ning L, Fang Z, Wang Y, Zhang L, Cheng J, Zhang W and Hao X: Differentially expressed genes between primary cancer and paired lymph node metastases predict clinical outcome of node-positive breast cancer patients. Breast Cancer Res Treat 103: 319-329, 2007.

20. Hao X, Sun B, Hu L, Lahdesmaki H, Dunmire V, Feng Y, Zhang SW, Wang H, Wu C, Wang H, Fuller GN, Symmans WF, Shmulevich I and Zhang W: Differential gene and protein expression in primary breast malignancies and their lymph node metastases as revealed by combined cDNA microarray and tissue microarray analysis. Cancer 100: 1110-1122, 2004.

21. Vecchi M, Confalonieri S, Nuciforo P, Vigano MA, Capra M, Bianchi M, Nicosia D, Bianchi F, Galimberti V, Viale G, Palermo G, Riccardi A, Campanini R, Diadone MG, Pierotti MA, Pece $S$ and DiFiore PP: Breast cancer metastases are molecularly distinct from their primary tumors. Oncogene 27: 2148-2158, 2008.

22. Dalerba P and Clarke MF: Cancer stem cells and tumor metastasis: First steps into uncharted territory. Cell Stem Cell 1: 241-242, 2007.

23. Shipitsin M, Campbell LL, Argani P, Weremowicz S, Bloushtain-Qimron N, Yao J, Nikolskaya T, Serebryiskaya T, Beroukhim R, Hu M, Halushka MK, Sukumar S, Parker LM, Anderson KS, Harris LN, Garber JE, Richardson AL, Schnitt SJ, Nikolsky Y, Gelman RS and Polyak K: Molecular definition of breast tumor heterogeneity. Cancer Cell 11: 259-273, 2007.

24. Al-Hajj M, Wicha MS, Benito-Hernandez A, Morrison SJ and Clarke MF: Prospective identification of tumorigenic breast cancer cells. Proc Natl Acad Sci USA 100: 3983-3988, 2003.

25. Shipitsin M and Polyak K: The cancer stem cell hypothesis: In search of definitions, markers, and relevance. Lab Invest 88 : 459-463, 2008.
26. Cailleau R, Olive M and Cruciger QV: Long-term human breast carcinoma cell lines of metastatic origin: preliminary characterization. In Vitro 14: 911-915, 1978.

27. Glinsky GV, Berezovska O and Glinskii AB: Microarray analysis identifies a death-from-cancer signature predicting therapy failure in patients with multiple types of cancer. J Clin Invest 115 : 1503-1521, 2005.

28. Liu R, Wang X, Chen GY, Dalerba P, Gurney A, Hoey T, Sherlock G, Lewicki J, Shedden K and Clarke MF: The prognostic role of a gene signature from tumorigenic breastcancer cells. N Engl J Med 356: 217-226, 2007.

29. Polyak K and Hahn WC: Roots and stems: stem cells in cancer. Nat Med 12: 296-300, 2006.

30. Sheridan C, Kishimoto H, Fuchs RK, Mehrotra S, BhatNakshatri P, Turner CH, Goulet R Jr, Badve S and Nakshatri H: CD $44^{+} / \mathrm{CD} 24^{-}$breast cancer cells exhibit enhanced invasive properties: An early step necessary for metastasis. Breast Cancer Res 8: R59, 2006

31. Kaplan RN, Rafii S and Lyden D: Preparing the 'soil': the premetastatic niche. Cancer Res 66: 11089-11093, 2006.

32. Chambers AF, Groom AC and MacDonald IC: Dissemination and growth of cancer cells in metastatic sites. Nat Rev Cancer 2: 563-572, 2002.

33. Chang CC: Recent translational research: stem cells as the roots of breast cancer. Breast Cancer Res 8: 103, 2006.

34. Balic M, Lin H, Young L, Hawes D, Giuliano A, McNamara G, Datar RH and Cote RJ: Most early disseminated cancer cells detected in bone marrow of breast cancer patients have a putative breast cancer stem cell phenotype. Clin Cancer Res 12: 5615-5621, 2006

35. Ginestier C, Korkaya H, Dontu G, Birnbaum D, Wicha MS and Charafe-Jaufrette E: The cancer stem cell: the breast cancer driver. Med Sci (Paris) 23: 1133-1139, 2007.

36. Wright MH, Calcagno AM, Salcido CD, Carlson MD Ambudkar SV and Vartikovski L: Brcal breast tumors contain

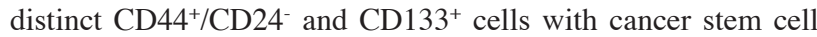
characteristics. Breast Cancer Res 10: R10, 2008.

37. Li L and Neaves WB: Normal stem cells and cancer stem cells: the niche matters. Cancer Res 66: 4553-4557, 2006

38. Li F, Tiede B, Massague J and Kang Y: Beyond tumorigenesis: cancer stem cells in metastasis. Cell Res 17: 3-14, 2007. 